\title{
Smoking and Depression among Healthcare Workers
}

\author{
Madhusudhan Ghimire ${ }^{\mathrm{a}, \mathrm{d}}$, Achala Sharma ${ }^{\mathrm{b}}$, Moushami Ghimire ${ }^{\mathrm{c}, \mathrm{d}}$
}

\begin{abstract}
:
Introduction: Healthcare workers are a special public icon for the community because people would like to adopt and implement their knowledge, skill, attitude and behaviour for improving quality of health. People respect them for their knowledge and health behavior. It is believed that the level of health status of health workers as well as community should go ahead parallel but many researchers have noted that high risk behaviours (smoking, tobacco use, alcoholism, irregular diet intake, lack of exercise etc.) are prevalent among health workers. The result of this will be physical, psychological, familial and social disturbance, which might have an impact on health care delivery system of the country. The study was concerned to assess health status (body mass index, smoking and depression) of healthcare workers and its impact on social adjustment in Banke district of Nepal. Methods: A cross sectional study design was applied to conduct the research. One hundred and eight respondents were selected through random sampling from the purposive group. Data wa collected through interview by using interview schedule. SPSS-16 windows process was used to analyze data. Results: Most of the respondent (81.40\%) were under the age group less than 30 years $(M=27.35, S D=9.24$ years). More than $57.40 \%$ of respondents were female. Most of them (68.50\%) were unmarried. Maximum (82.20\%) responders had normal Body Mass Index (18.5-24.99). Near about forty percent (38.9\%) healthcare worker had faced social problems in their working area. Conclusion: Age (above 20 years) and male healthcare workers were more likely to smoke cigarettes. Depressed health workers were more likely to smoke cigarette. Depression could be observed as a determinant for social adjustment.
\end{abstract}

Keywords: depression • health workers • smoking • social problems

\section{INTRODUCTION:}

Healthcare worker always try to understand the role of an individual in the society, social structure, stratification, issues related to caste, class and gender, socio-economic and political factors and their impact on society. They also try to understand various social problems and its impact on the society, various issues and challenges, attitudes and skills

\footnotetext{
a - Assistant Professor

b - School of Social Science,

Jaipur National University, Jaipur, India

c - Lecturer

d - Department of Community Medicine,

Lumbini Medical College, Palpa, Nepal.
}

Corresponding Author:

Dr. Madhusudan Ghimire

e-mail: madhumds@gmail.com

How to cite this article:

Ghimire M, Sharma A, Ghimire M. Smoking and depression among healthcare workers. Journal of Lumbini Medical College. 2014;2(1):21-4. doi: 10.22502/jlmc.v2i1.50. appropriate for social work, problems related to industrial hazards, occupational diseases and its safety management. ${ }^{1}$ World Health Assembly recognized that occupational health is closely linked to public health and the development of health systems. World Health Organization (WHO) is addressing all determinants of workers' health, including risks for disease and injury in the occupational environment, social and individual factors, and access to health services. Furthermore, the workplace is being used as a setting for protecting and promoting the health of workers and their families. ${ }^{2}$ Many studies state that poor treatment or inadequate service, control over health professionals, excessive workload, inadequate facilities and lack of materials are the common issues that might be sources of frustration for many health workers. These factors affect their motivation, which in turn affects their performance and social adjustment. ${ }^{3}$ Therefore, occupational stress is rising due to continuing structural changes in the workplace, demands and job insecurity 
imposed on employees. ${ }^{4}$ Some behavioral factors like dietary pattern, alcohol intake, cigarette smoking, carelessness in family and social relationship of health workers may impact on holistic aspects of community health. Tobacco smoking has numerous, well-documented, adverse health effects, both alone and in combination with hazardous workplace exposures. People who work may be active smokers. ${ }^{5}$ It has been estimated that four fifths of the estimated 1.1 million smokers live in low and middle-income countries. ${ }^{6}$ It is responsible for considerable number of morbidity and mortality in the world. It is one of the most important preventable risk factor of most non communicable diseases. ${ }^{7}$ WHO estimated that approximately 5 million people die each year worldwide from tobacco related illnesses. If current trend continues, this figure will rise to about 10 million per year by $2025 .^{8}$

The objective of this study was to assess health status (BMI, smoking and depression) of healthcare workers and its impact on social adjustment in Banke district of Nepal.

\section{METHODS:}

A cross sectional study design was applied to

Table 1: Demographic profile of respondents $(N=108)$.

\begin{tabular}{|c|c|c|c|}
\hline Variables & & $N$ & $\%$ \\
\hline \multirow{3}{*}{$\begin{array}{l}\text { Age in years } \\
(\mathbf{M}=27.35 \\
\text { SD=9.24) }\end{array}$} & $\leq 30$ & 88 & 81.40 \\
\hline & $31-50$ & 12 & 11.00 \\
\hline & $>50$ & 8 & 7.60 \\
\hline \multirow{2}{*}{ Sex } & Male & 46 & 42.60 \\
\hline & Female & 62 & 57.40 \\
\hline \multirow{2}{*}{ Marital status } & Married & 34 & 31.50 \\
\hline & Unmarried & 74 & 68.50 \\
\hline \multirow{2}{*}{$\begin{array}{l}\text { Nature of } \\
\text { Organization }\end{array}$} & Government & 34 & 31.50 \\
\hline & Private & 74 & 68.50 \\
\hline \multirow{4}{*}{$\begin{array}{l}\text { Nature of } \\
\text { Occupation }\end{array}$} & Medical & 38 & 35.20 \\
\hline & Public health & 20 & 18.50 \\
\hline & Nursing & 38 & 35.20 \\
\hline & Laboratory & 12 & 11.10 \\
\hline \multirow{3}{*}{ Body mass index } & Below 18.5 & 2 & 2.00 \\
\hline & 18.5 to 24.99 & 83 & 82.20 \\
\hline & Above 25 & 16 & 15.80 \\
\hline \multirow{2}{*}{ Depression } & Yes & 18 & 16.7 \\
\hline & No & 90 & 83.3 \\
\hline \multirow{2}{*}{ Social problem } & Yes & 42 & 38.9 \\
\hline & No & 66 & 61.1 \\
\hline \multirow{2}{*}{ Cigarette smoking } & Yes & 42 & 38.9 \\
\hline & No & 66 & 61.1 \\
\hline
\end{tabular}

conduct the study during the month of March 2014 in Banke district of Nepal. One hundred and eight respondents were selected through simple random sampling from the purposive group. A pretest procedure applied in order to verify the reliability and validity of research tools. Data were collected through unstructured questionnaire. Anonymity and secrecy of all participants and their wishes and expressions were maintained. After completing the data collection, SPSS-16 was used to analyze the information. Frequency distribution, mean, standard deviation and statistical test were applied to interpret the results.

\section{RESULTS:}

Table 1 shows the demographic profile of the participants. A chi-square test of independence was applied to examine the relation between social problem and sex. The relation between these variables was significant, $X^{2}(1,108)=10.48, p<$ 0.001 . Male healthcare workers were more likely to face social problem than were females. Relation between age and sex with cigarette smoking is shown in Table 2. It shows male healthcare workers were more likely to smoke than females, similarly workers 20 years or older were more likely to smoke than the youngers. Table 3 shows relation between depression with cigarette smoking, social problems and gemder. It shows that the depressed are more likely to smoke, have social problems and are males.

Table 2: Relation of age and sex with cigarette smoking

\begin{tabular}{llccl}
\hline & & Smoker & Non Smoker & \\
\hline \multirow{2}{*}{ Age(yr) } & $<\mathbf{2 0}$ & 0 & 16 & $p<0.001$ \\
& $\geq \mathbf{2 0}$ & 42 & 50 & Fisher exact \\
\multirow{2}{*}{ Sex } & M & 30 & 16 & $X^{2}=23.372$ \\
& F & 12 & 50 & $p<0.001$ \\
\hline
\end{tabular}

Table 3: Relation of Depression with smoking, social problem and sex

\begin{tabular}{ccccl}
\hline & \multicolumn{4}{c}{ Depression } \\
& & yes & no & \\
\hline \multirow{2}{*}{ Smoking } & yes & 14 & 28 & $X^{2}=13.75$ \\
& no & 4 & 62 & $p<0.001$ \\
Social & yes & 16 & 26 & $X^{2}=22.72$ \\
problem & no & 2 & 64 & $p<0.001$ \\
& male & 12 & 34 & $X^{2}=5.12$ \\
Sex & female & 6 & 56 & $p=0.024$ \\
\hline
\end{tabular}




\section{DISCUSSION:}

This cross-sectional study has concerned to analyze behavioural health from the 108 healthcare workers in Banke district of Nepal. Most of the respondent (66.60\%) were under the age group below 30 years $(M=27.35, S D=9.243)$. More than fifty seven percent $(57.40 \%)$ respondents were female. Most of them (68.50\%) were unmarried. Regarding the nature of occupation, 35.20\%, 18.50\%, 35.20\% and $11.10 \%$ respondents were medical, public health, nursing and laboratory workers respectively. More than two-third respondents (68.50\%) were working in private sectors. In this study, 82.20\% had normal Body Mass Index (18.5-24.99) which was quite high as compared to the $57.40 \%$ of adult male population who had normal range of BMI in a study in Dharan, Nepal. ${ }^{9}$ Overweight or obese (BMI $\geq 25 \mathrm{~kg} / \mathrm{m} 2$ ) were $7.2 \%(4.8 \%-9.5 \%)$ in general population of Nepal. ${ }^{10}$ The study explored that the prevalence of BMI $\geq 25 \mathrm{~kg} / \mathrm{m}^{2}$ among the healthcare worker was $15.80 \%$ which was quite less as compared to the figure of employees in Belgium and Shiraz hospital staffs in Iran where the prevalence of a BMI $\geq 25 \mathrm{~kg} /$ $\mathrm{m}^{2}$ was $48.50 \%$ and $27.8 \%$ respectively. ${ }^{12}$

Noteworthy tobacco use was found among undergraduate medical students. This harmful behaviour not only causes personal harm but also reduces health professionals' ability to motivate or counsel the patients effectively. ${ }^{13}$ Morrell et al. found that prevalence of smoking was $16.8 \%$ among students ofhealthprofessionals whichwasmuchlower than the rates observed among their undergraduate peers. ${ }^{14}$ Smoking prevalence was $40.5 \%$ (95\% CI: 33.6-47.4) in males, $23.5 \%$ (95\% CI: 19.2-27.8) in females ( $p<0.001$ ); $43.2 \%$ in auxillaries, $26.1 \%$ in nurses, $18.9 \%$ among physicians, and $34.7 \%$ among other non-health professionals $(p<0.05)$ in a Portuguese teaching hospital. ${ }^{15}$ Uprety et al. stated that the prevalence of smokers was higher in the age group after 35 years and friends and family members who smoke were found to be common reasons for early initiation of smoking. ${ }^{16}$ Another study from Dharan acknowledged that young people were more vulnerable to start cigarette smoking. Male populations of Dharan were actively involved in smoking with prevalence of $41.7 \%$ which was slightly higher than the prevalence of smoking estimated as $38.4 \%$ among male medical and dental students of B.P. Koirala Institute of Health Sciences, Dharan, Nepal. ${ }^{17,18}$ The study revealed that $38.90 \%$ of healthcare workers had smoked (tobacco smoking) multiple times during their life and this was higher than the prevalence of smoking (28\%) reported at the National Institutes of Health in Mexico. ${ }^{19}$ The study found that cigarette smoking was determined by age and sex of healthcare workers and the association with both age and sex was $(p<0.001)$. Different studies remarked that the prevalence of tobacco smoking was considerably high among Nepalese people. Nepal also has a very high prevalence rate of chronic obstructive lung disease (COLD) varying from $20-40 \%$ in persons above the age of twenty years which was found to be significantly associated with tobacco smoking. ${ }^{20,21}$ Near about forty percent (38.9\%) health worker had faced social problems in their working area.

It is indicated that psychosocial stress at work might be a relevant risk factor for depressive symptoms among older employees across countries and continents. $^{22}$ Wall TD. et al. found that healthcare workers generally have psychological morbidity rates higher than the general population. In a large NHS sample in the UK, the relative risk of disorder was 1.5 and was most marked in direct care staff and women. ${ }^{23}$ An analysis of the combined sample gave an overall prevalence of depressive disorders in $8.56 \%$ (95\% CI 7.05-10.37) of general population in five European countries. The figures were $10.05 \%$ (95\% CI 7.80-12.85) for women and $6.61 \%$ (95\% CI 4.92-8.83) for men. ${ }^{24}$ The largest population-based study from India reported that the prevalence of depression among urban South Indians was $15.1 \%$. Age, female gender and lower socio-economic status were associated with depression in that population. ${ }^{25}$ The prevalence of depression among the Nepalese Rai older adults was $29.7 \% .{ }^{26}$ The prevalence of depression was $51.3 \%$ in geriatric home in Kathmandu valley. ${ }^{27}$ The study revealed that $16.70 \%$ of health workers (both male and female) were depressed and sex was found to be a determinant factor for depression in working place $(p<0.05)$ where male were supposed to be three times at a higher risk than females. It was also found that depression was significantly associated with cigarette smoking $(p<0.001)$ and faced problem for social adjustment $(p<0.001)$. It could be uncovered that depressed health workers were 7.75 and 19.69 times higher exposed to cigarette smoking and faced social problems compared to non smokers and healthcare worker who could not face social problem in working area respectively. 
Ghimire M. et al. Smoking and depression among healthcare workers.

\section{CONCLUSION:}

Most of the healthcare workers had normal BMI. Helathworkers of age above 20 years and males were more likely to smoke cigarette. Depressed healthworkers are more likely to smoke, have social problems and are males.

\section{REFERENCES:}

1. World Health Organisation. WHO report on Health systems financing, 2010: The path to universal coverage. World Health Organisation; 2010.

2. Neira M. World Health Organisation. WHO Global Plan of Action on Workers Health, 2008-2017. Promoting a Preventative Safety and Health Culture: International Instruments, national strategies and good practices. Geneva: ILO International Safety Conference; 2011.

3. Cassitto MG, Fattorini E, Gilioni R, Rengo C, Gonik V. Raising Awareness of Psychological Harassment at Work: Protecting Workers' Health Series No 4. World Health Organisation, 2003.

4. Tennant C. Work-related stress and depressive disorders. J Psychosom Res. 2001;51(5):697-704.

5. Work, Smoking, and Health. A NIOSH Scientific Workshop. Washington DC: Center for Disease Control and Prevention; 2000.

6. Jha P, Chaloupka FJ, Moore J, Gajalakshmi V, Gupta PC, Peck R, et al. Tobacco Addiction. In: Jamison DT, Breman J, Alleyne G, Claeson M, Evans DB, Jha P, et al (eds.). Disease Control Priorities in Developing Countries (2nd edition). Washington DC: Oxford University Press; 2006.p.869-86.

7. World Health Organization .Tobacco or health: A Global status report. Geneva: World Health Organization; 1997.

8. Tobacco frees Initiative (TFI): Report of Activities 20032004: WHO/ Non communicable disease and Mental Health. Geneva: World Health Organizatio; 2004.

9. Vaidya A, Pokharel PK, Nagesh S, Karki P, Kumar S, Majhi S. Association of obesity and physical activity in adult males of Dharan, Nepal. Kathmandu Univ Med J. 2006 Apr-Jun;4(2):192-7.

10. WHO STEPS Surveillance: Non Communicable Disease Risk Factors Survey, 2007/2008, Nepal. Geneva: World Health Organisation; 2008.

11. Moens G, Gaal LV, Muls E, Viaene B, Jacques P. Body mass index and health among the working population: Epidemiologic data from Belgium. Eur J Public Health. 1999;9(2):119-23. doi: 10.1093/eurpub/9.2.119.

12. Sahebi R, Seyyedi M, Sahebi L, Nezhad RR. Epidemiology of Overweight and Obesity among the Workers of Shiraz Hospitals. Ind J Fund Appl Life Sci. 2014;4(2):177-84.

13. Aggarwal P, Varshney S, Kandpal SD, Gupta P. Habits and beliefs pertaining to tobacco among undergraduates of a medical college in the state of Uttarakhand. Journal Indian Academy of Clinical Medicine. 2012;13(3):189-94.

14. Morrell HER, Cohen LM, Dempsey JP. Smoking Prevalence and Awareness among Undergraduate and Health Care Students. Am J Addict, 2008;17(3):181-6. doi: 10.1080/10550490802019899.

15. Ravara SB, Calheiros JM, Aguiar P, Barata LT. Smoking behaviour predicts tobacco control attitudes in a high smoking prevalence hospital: A cross-sectional study in a Portuguese teaching hospital prior to the national smoking ban. BMC Public Health. 2011;11:720. doi: 10.1186/14712458-11-720.

16. Uprety S, Poudel IS, Bhattarai S, Ghimire A, Singh N, Poudel M, et al. Knowledge on health effects and practices of smoking among the smokers in the Eastern Terai Region of Nepal. Journal of Chitwan Medical College. 2014;4(1):22-5. doi.org/10.3126/jcmc.v4i1.10843.

17. Poudel S, Gurung DK. Prevalence of smoking and perceived health problems among male population of Dharan municipality. Journal of Kathmandu Medical College. 2013;2(3):129-38.

18. Ghimire A, Sharma B, Niraula SR, Devkota S, Pradhan PM. Smoking Habit among Male Medical and Dental Students of B.P.Koirala Institute of Health Sciences, Nepal. Kathmandu Univ Med J. 2013;41(1):32-6.

19. Sansores RH, Caloca JV, Kiengelher LH, Rodriguez AS, Venegas AR. Prevalence of cigarette smoking among employees of the Mexican National Institute of Health. Salud Publica Mex. 1999;41(5):381-8.

20. Sreeramareddy CT, Ramakrishnareddy N, Kumar HNH, Sathian B, Arokiasamy JT. Prevalence, distribution and correlates of tobacco smoking and chewing in Nepal: a secondary data analysis of Nepal Demographic and Health Survey-2006. Subst Abuse Treat Prev Pol. 2011;6:33. doi: 10.1186/1747-597X-6-33.

21. Pandey MR, Basnyat B, Neupane RP. Chronic bronchitis and Cor Pulmonale in Nepal. Monograph: Mrigendra Medical Trust; 1988.

22. Siegrist J, Lunau T, Wahrendorf $M$, Dragano $M$. Depressive symptoms and psychosocial stress at work among older employees in three continents. Global Health 2012 Jul;8:27. doi: 10.1186/1744-8603-8-27.

23. Wall TD, Bolden RI, Borrell CS, Carter AJ, Golya DA, Hardy GE, et al. Minor psychiatric disorder in NHS trust staff: occupational and gender differences. Br J Psychiatry. 1997 Dec;171:519- 23.

24. Ayuso-Mateos JL, Vazquez-Bargurero JL, Dowrick C, Lehtinen V, Dalgard OS, Casey P, et al. Depressive disorders in Europe: prevalence figures from the ODIN study. Br J Psychiatry. 2001 Oct;179:308-16. doi:10.1192/ bjp.179.4.308.

25. Patel V, Weiss HA, Chowdhary N, Naik S, Pednekar S, Chatterjee S, et al. Lay health worker led intervention for depressive and anxiety disorders in India: impact on clinical and disability outcomes over 12 months. Br J Psychiatry. 2011 Dec;199(6):459-66. doi: 10.1192/bjp. bp.111.092155.

26. Chalise HN, Rai SL. Prevalence and Correlates of Depression among Nepalese Rai Older Adults. J Gerontol Geriat Res. 2013;2:130. doi:10.4172/2167-7182.1000130.

27. Choulagai PS, Sharma CK, Choulagai BP. Prevalence and Associated Factors of Depression among Elderly Population Living in Geriatric Homes in Kathmandu Valley. Journal of Institute of Medicine. 2013; 35(1):39-44. 